\title{
Melting and Heat Transfer Characteristics of Urea Water Solution According to a Heating Module's Operating Conditions in a Frozen Urea Tank
}

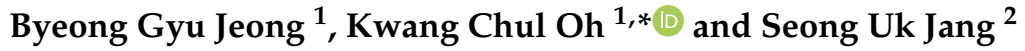 \\ 1 Korea Automotive Technology Institute, Cheonan-si 31214, Korea; joengbg@katech.re.kr \\ 2 Sejong e-R\&D Center, 120, Yongin-si 16950, Korea; swjang@sjku.co.kr \\ * Correspondence: kcoh@katech.re.kr; Tel.: +82-041-559-3089; Fax: +82-041-559-3242
}

Citation: Jeong, B.G.; Oh, K.C.; Jang, S.U. Melting and Heat Transfer Characteristics of Urea Water Solution According to a Heating Module's Operating Conditions in a Frozen Urea Tank. Energies 2021, 14, 8164. https://doi.org/10.3390/en14238164

Academic Editor: Massimo Cardone

Received: 29 September 2021

Accepted: 1 December 2021

Published: 6 December 2021

Publisher's Note: MDPI stays neutral with regard to jurisdictional claims in published maps and institutional affiliations.

Copyright: () 2021 by the authors. Licensee MDPI, Basel, Switzerland. This article is an open access article distributed under the terms and conditions of the Creative Commons Attribution (CC BY) license (https:// creativecommons.org/licenses/by/ $4.0 /)$.

\begin{abstract}
The urea-selective catalytic reduction (SCR) system, a nitrogen oxide reduction device for diesel vehicles, is a catalytic system that uses urea water solution (UWS) as a reducing agent. This system has a relatively wide range of operating temperatures. However, the freezing point of the reducing urea solution used in this system is $-11^{\circ} \mathrm{C}$. When the ambient temperature dips below this freezing point in winter, the solution may freeze. Therefore, it is important to understand the melting characteristics of frozen UWS in relation to the operating conditions of the heating device to supply the minimum amount of aqueous solution required by the system in the initial stage of normal operation and startup of the urea-SCR system. In this study, we artificially froze a liquid solution by placing it along with a heating module in an acrylic chamber to simulate a urea solution tank. Two types of heating modules (P120 and P160) consisting of two heating elements and heat transfer bodies were used to melt the frozen solution. The melting characteristics of the frozen solution were observed, for example, changes in the temperature distribution around the heating module and the cross-sectional melting shape with the passage of time since the start of the power supply to the heating module. The shape of melting around the heating module differed depending on the level of UWS relative to the heater inside the urea tank. In case 1, it melted in a wide shape with an open top, and in case 2, it melted in a closed shape. This shape change was attributed to the formation of internal gaseous space due to volume reduction during melting and the heat transfer characteristics of the fluid and solid substances.
\end{abstract}

Keywords: urea-selective catalytic reduction (urea-SCR); urea water solution (UWS); heating module; PTC heater; urea melting; melting shape

\section{Introduction}

Automotive diesel engines generally offer the advantages of higher power and fuel economy and lower $\mathrm{CO}_{2}$ emissions, compared with those of gasoline engines. However, diesel engines, which involve compression ignition, emit significant amounts of particulate matter $(\mathrm{PM})$ and nitrogen oxide $\left(\mathrm{NO}_{\mathrm{x}}\right)$ because of the coexistence of local fuel-rich points and hot flame zones in the combustion chamber [1-3]. PM comprises extremely small particles, and it contains various heavy metals and pollutants that can penetrate the lungs and blood vessels and cause human health problems [4]. Moreover, $\mathrm{NO}_{\mathrm{x}}$ is harmful to humans, and it also destroys the ozone layer and creates optical smog $[5,6]$. To solve these problems, measures such as improving combustion within the engine itself, high-pressure fuel injection, and exhaust gas recirculation (EGR) have been developed. However, as emission regulations become increasingly stringent, these engine-technology-related measures alone are proving to be inadequate. For this reason, various companies and research institutes continue to study after-treatment systems for internal combustion engine vehicles. The existing commercially available diesel particulate filters (DPFs) provide a PM reduction rate of nearly $90 \%[7,8]$. Similarly, $\mathrm{NO}_{x}$ emissions are being continuously reduced using 
various devices, including lean $\mathrm{NO}_{x}$ traps (LNTs), urea-selective catalytic reduction (ureaSCR), and hydrocarbon-selective catalytic reduction (HC-SCR) systems [9-11]. Among them, in urea-SCR systems, urea is used as a reducing agent in an aqueous solution that is in the liquid state at room temperature and generates ammonia at a temperature of approximately $150{ }^{\circ} \mathrm{C}$ or higher. The generated ammonia $\left(\mathrm{NH}_{3}\right)$ reduces nitrogen oxides to substances that are harmless to the human body, such as $\mathrm{H}_{2} \mathrm{O}$ and $\mathrm{N}_{2}$, through the catalytic activity of zeolite-containing active metals $[8,12,13]$. Compared with other $\mathrm{NO}_{\mathrm{x}}$ reduction devices, this system has a wide catalyst activation temperature range. Therefore, its $\mathrm{NO}_{\mathrm{x}}$ reduction efficiency is relatively stable under actual driving conditions $[14,15]$. For this reason, urea-SCR systems are currently being installed in many diesel vehicles, and studies on the optimization of components and systems are ongoing.

The urea water solution (UWS), used as a reducing agent in urea-SCR systems, contains $32.5 \%$, and its freezing point is approximately $-11^{\circ} \mathrm{C}$ [16]. For this reason, the supply of the reducing agent may be hampered owing to the freezing of the UWS in the climates of northern Europe or North America, where the ambient temperatures are lower than the freezing point of the solution. In this case, because the UWS is not supplied, proper SCR system operation is hampered, which may lead to significant $\mathrm{NO}_{\mathrm{x}}$ emission. Due to this problem, the United States Environmental Protection Agency (US EPA) requires that UWS spray be supplied from completely frozen UWS approximately 20 min after an engine is started (depending on the tank temperature) when the ambient temperature is $-16^{\circ} \mathrm{C}$, as shown in Figure 1 [17].

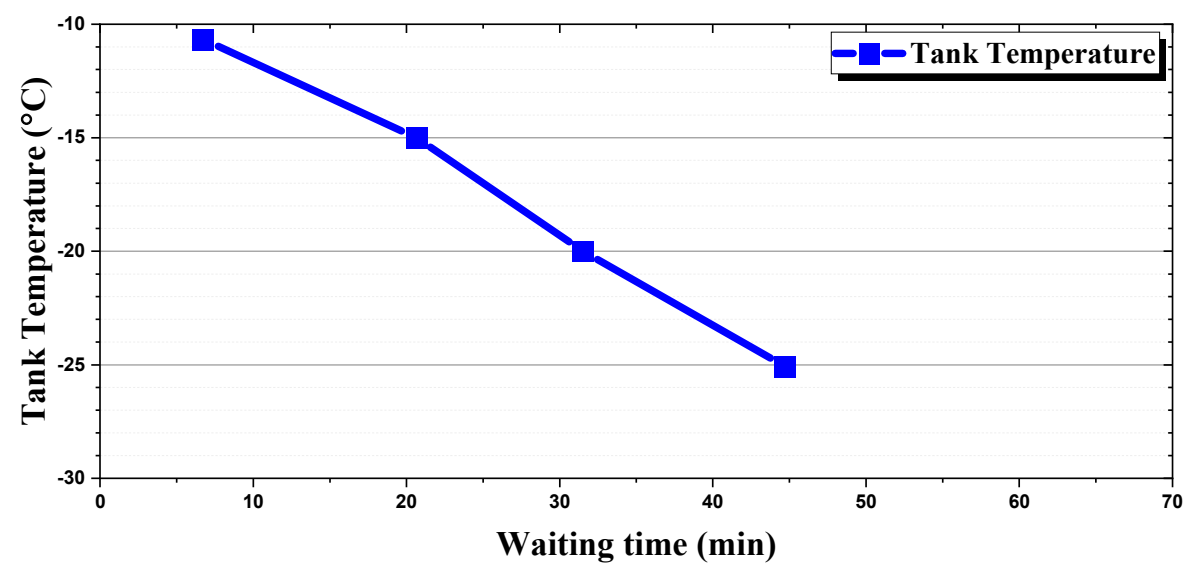

Figure 1. AdBlue defrost concept [17].

Several methods are used to solve the UWS freezing problem, one of which involves placing a heat source inside the UWS tank. In large vehicles, space is not a constraint, and the tank adequately is large. Therefore, a coil-type heater and engine coolant are used as the heat sources to defrost the UWS. In passenger vehicles, which have relatively small tanks, an electric heater is used for defrosting the UWS.

Stefan et al. analyzed the melting of UWS by using a numerical analysis model in which an electric heating module was applied to an AdBlue Tank (UWS Tank) [18]. LLC Chrysler et al. conducted a numerical analysis of the freezing and melting characteristics of a UWS tank by applying the method that uses the heat of the engine coolant and compared it with the operation test [19]. Choi et al. applied a method that uses the heat of engine coolant to experimentally study the melting characteristics of UWS in a tank with the aim of ensuring that adequate UWS is consumed by the urea-SCR system of a vehicle at start-up; in addition, they performed a numerical analysis to determine the optimal shape of heating coils $[20,21]$. Lee et al. conducted a numerical analysis study by applying engine coolant heat and electric heating and found electric heating to be more efficient than the method that uses engine coolant heat $[22,23]$.

However, most existing studies on UWS melting are based on numerical analysis or pertain to the amount of melting. There is a lack of studies on the shape of melting around 
the heater during the actual melting process. Even if a sufficient amount has been melted, pumping cannot be performed if the inlet and outlet of the pump are in unmelted positions. Due to this reason, when developing a dosing device, it is important to determine the positions of the suction and return ports between the liquid UWS inside the tank and the dosing pump.

Therefore, in this study, we holistically investigated the melting characteristics of UWS frozen in a tank. The mass of melt and the temperature distribution around the heater during the melting process were examined after supplying power using two types of heater elements with variable resistance to temperature. Moreover, changes in the shape of melting depending on the UWS level were investigated to determine the position of the suction and return ports in a UWS tank with a dosing pump integrated into it.

\section{Experimental Setup and Method}

Figure 2 shows the configuration of the test equipment used herein to determine the melting characteristics of frozen UWS. A transparent chamber (internal dimensions: Diameter $=140 \mathrm{~mm}$, Height $=90 \mathrm{~mm}$ ) made of acrylic was fabricated to simulate the tank mentioned in the preceding section because the urea solution tanks used in vehicles are bulky, and it is difficult to observe any changes in the UWS with the naked eye as the UWS melts. The heating module was located at the center of the acrylic chamber, as shown in Figure 2a. Power was supplied by connecting the two heating element power pins protruding from the hole under the chamber in parallel, as in Figure $2 \mathrm{~b}$. The voltage supplied to each heating element was $24 \mathrm{~V}$, and the power consumption over time, mass of melt, shape of melting, and temperature change characteristics around the heating module were investigated.
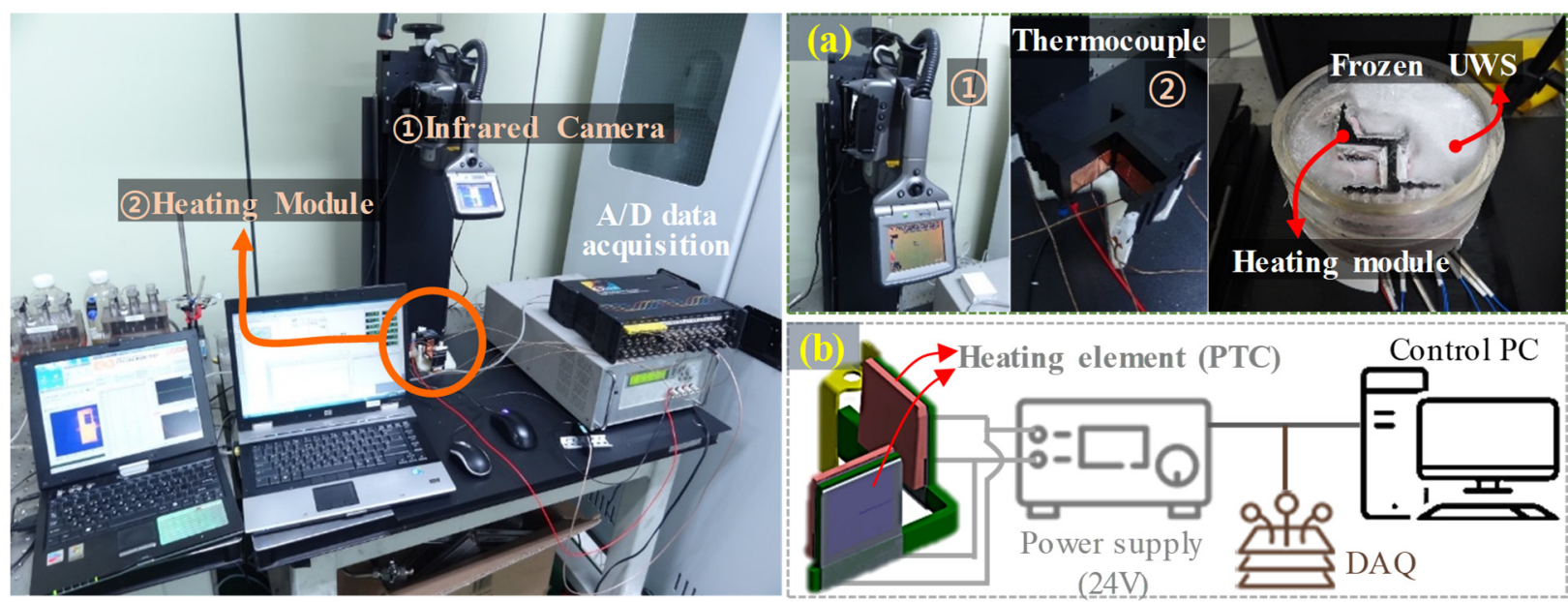

Figure 2. Experimental setup for urea melting test: (a) thermal melting characteristics; (b) heater power supply.

Figure 3 shows the shape of the heating module used in the test. The module consisted of two heating elements inserted inside the tank. The heat generated from the elements was transferred to the UWS by the heat dissipation module. The heat dissipation module was made of aluminum, and it had protrusions to increase the surface area for spreading the heat generated by the heating element at a faster rate.

Two types of heating modules were used in this study, and they were classified depending on their characteristics of resistance to temperature. The heating elements of Module_1 and Module_2 had temperature limits of approximately $120^{\circ} \mathrm{C}$ and $160{ }^{\circ} \mathrm{C}$, respectively, and the specifications of the module and the elements are summarized in Table 1. Figure 4 shows resistance measured based on the temperatures of two types of heating elements. The resistance of each element increased rapidly when the temperature was close to $120^{\circ} \mathrm{C}$ and $160{ }^{\circ} \mathrm{C}$, respectively. In addition, convergence to the limited 
temperature occurred within a short time by using a thermocouple and an IR camera to confirm the heat transfer characteristics to the entire module.
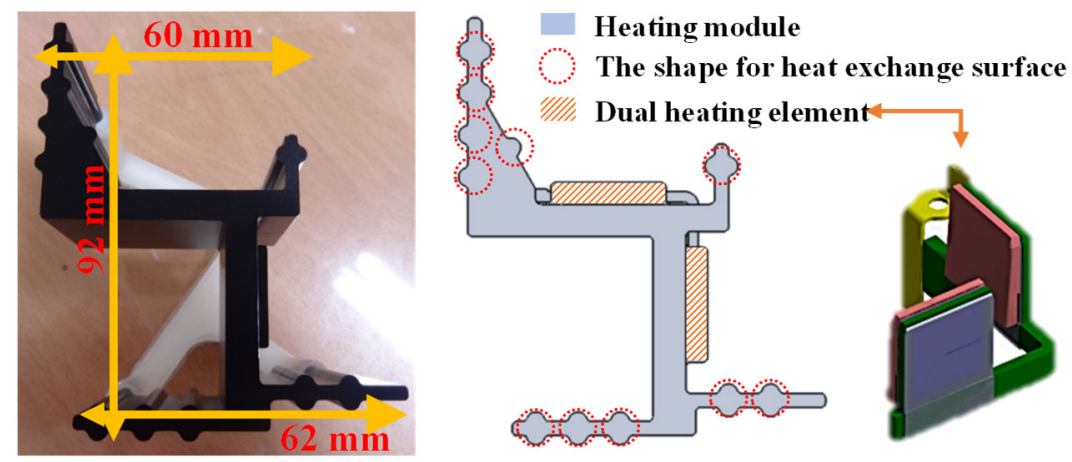

Figure 3. Heating module and heating elements.

Table 1. Specifications of heating module and PTC thermistor.

\begin{tabular}{cccc}
\hline & Variable & Unit & Value \\
\hline & Material & - & AL606 \\
Heating module & Density & $\mathrm{kg} / \mathrm{m}^{-3}$ & 2700 \\
& Specific Heat & $\mathrm{J} / \mathrm{kg} \cdot \mathrm{K}$ & 900 \\
& Thermal conductivity & $\mathrm{W} / \mathrm{m} \cdot \mathrm{K}$ & 170 \\
PTC thermistor & Power supply & Voltage & 24 \\
(Heating elements) & Limit Temp. & ${ }^{\circ} \mathrm{C}$ & 120,160 \\
\hline
\end{tabular}

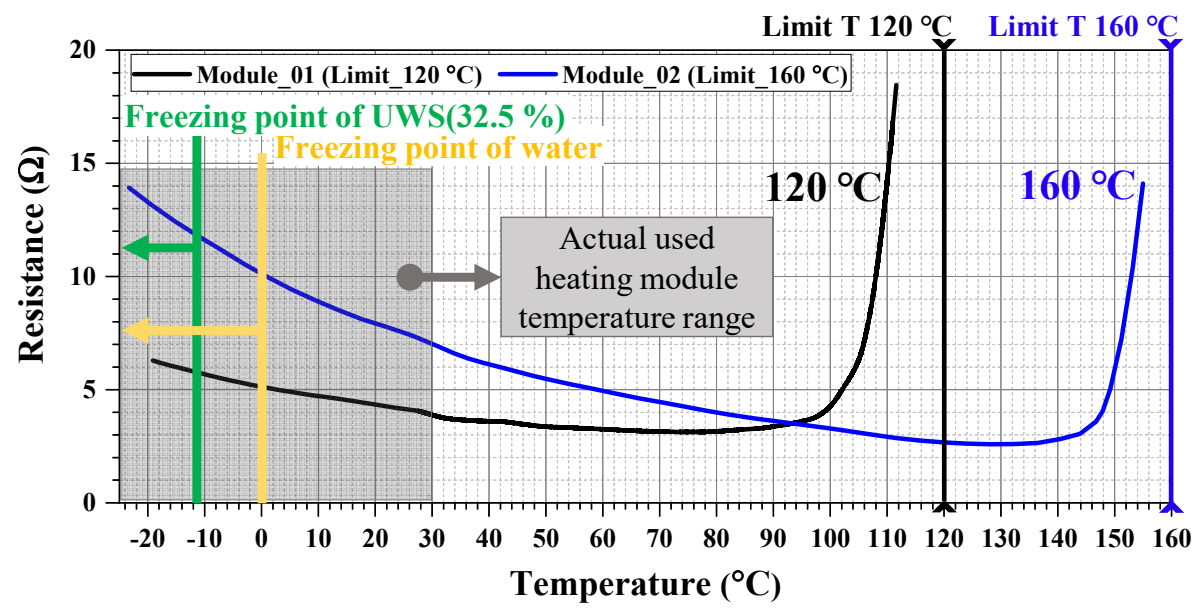

Figure 4. Heating element resistance according to temperature.

The photograph in Figure 5 shows the frozen state of the UWS, the melting characteristics of which are observed herein. Figure 5 a shows the frozen state of the UWS, and Figure $5 b$ shows the frozen state of water $\left(\mathrm{H}_{2} \mathrm{O}\right)$. In Figure $5 \mathrm{a}$, UWS is very opaque and white in color when frozen, and it is impossible to observe what lies below its surface and any changes that occur over time in the melting process. However, as shown in Figure 5b, when water $\left(\mathrm{H}_{2} \mathrm{O}\right)$ is used, it is relatively easier to observe the melting shape and characteristics. For this reason, except for some conditions considered in the test conducted to measure the mass of melt, distilled water $\left(\mathrm{H}_{2} \mathrm{O}\right)$ was used as a solution to study the melting shape characteristics during the melting process (water level and heating module). The density and enthalpy of distilled water and UWS at the same temperature are shown in Table 2. To simulate UWS frozen inside a real tank, UWS was artificially frozen inside a freezer that can reduce the temperature to less than $-20^{\circ} \mathrm{C}$. To examine the shape of melting, the inside of the acrylic chamber was divided using thin plates when the solution 
was in the liquid state. Subsequently, the chamber containing the liquid and the dividing plates was placed in the freezer. To initiate the melting process, power was supplied to the heating module for a predefined period of time. Thereafter, the unmelted part was removed from the chamber, and its shape was examined. The amount of melted solution was measured using a weighing scale with a resolution of 1/1000 $\mathrm{g}$ (AND GX-1000).

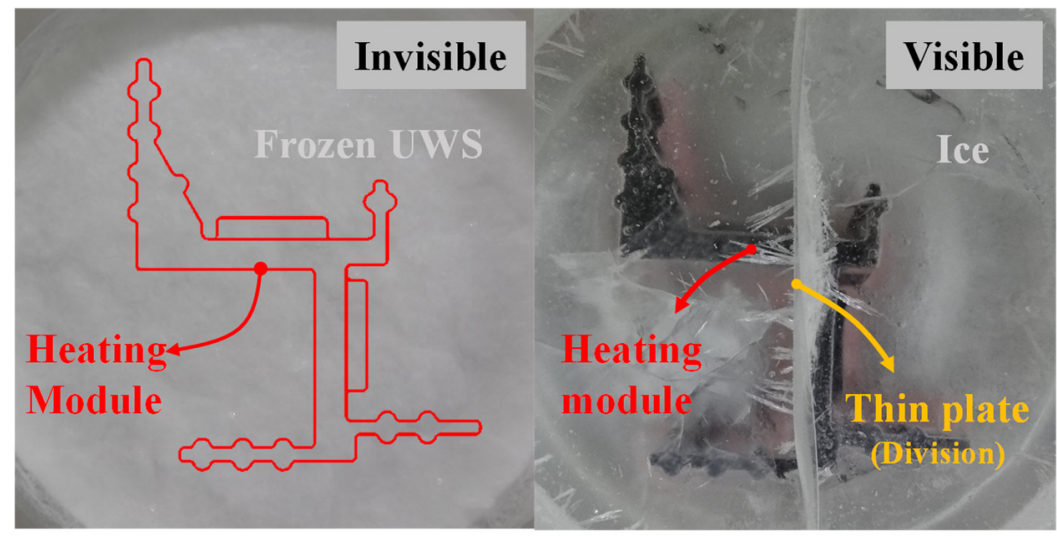

(a) Urea water solution

(b) Distilled Water

Figure 5. Visualization of frozen solution: (a) Urea water solution; (b) Distilled water.

Table 2. Specifications of Solution.

\begin{tabular}{cccc}
\hline & Distilled Water & Urea Water Solution & Unit \\
\hline Density $\left(20^{\circ} \mathrm{C}\right)$ & 0.9982 & $1.0870-1.0930$ & $\mathrm{~g} / \mathrm{cm}^{3}$ \\
Melting enthalpy & 333.55 & 270 & $\mathrm{~J} / \mathrm{g}$ \\
\hline
\end{tabular}

Figure 6 shows the location of the temperature sensor installed depending on the type of heating module to measure the solution temperature over time. $9 \mathrm{~K}$-Type thermocouples with a diameter of $0.5 \mathrm{~mm}$ were used as the temperature sensors.
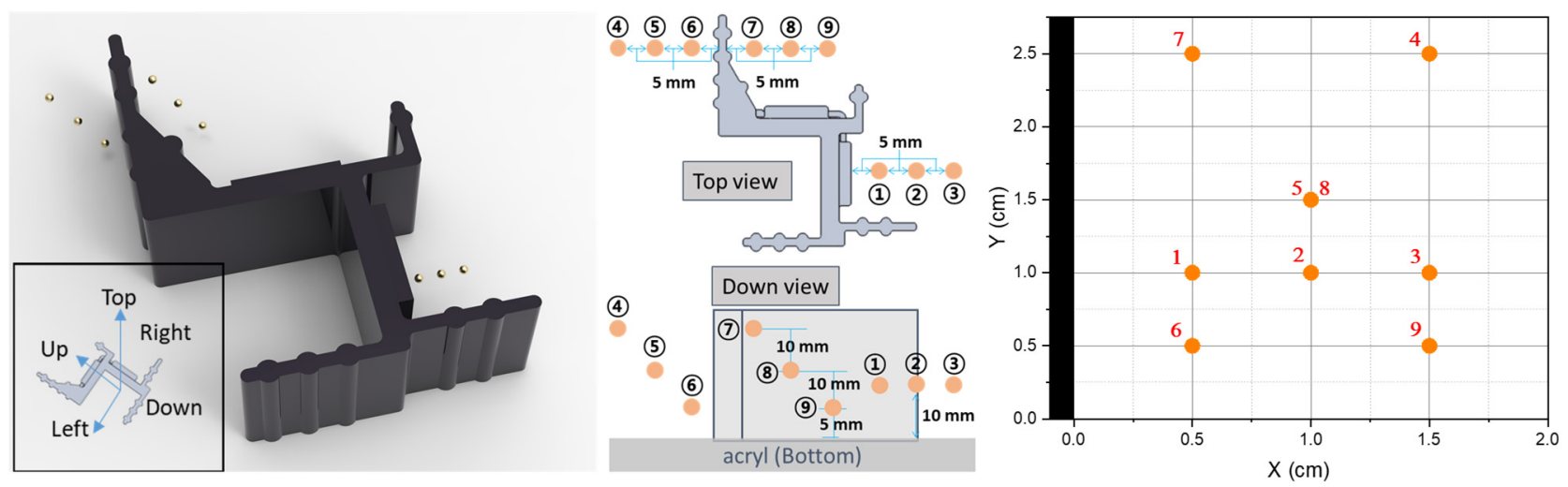

Figure 6. Heating module and temperature measurement points around the heater.

\section{Results and Discussion}

\subsection{Melting Shape}

In this study, because the shape of the heater was fixed, the thawed shape was investigated considering the water level of the solution. The level of the solution was into cases Case_1 and Case_2, as follows:

Case_1: Level of solution $\sim$ Surface of the heating module;

Case_2: Level of solution $>$ Surface of the heating module. 
Figure 7 shows an image of the melting shape at $420 \mathrm{~s}$ in Case_1 and a schematic diagram explaining the melting process in detail. The test results confirmed that the solution temperature increased relatively rapidly in regions close to the heating module, and the solution in these regions melted first. At this time, buoyancy was generated because of the temperature difference generated during the melting process, and the melted solution traveled upward along the module. In this process, if the ambient air temperature (test condition temperature: approximately $25^{\circ} \mathrm{C}$ ) was similar to or higher than the temperature of the melted solution, heat loss was delayed, or heat inflow occurred. Thereafter, heat loss occurred again, reaching the frozen solution that had not been melted, and it sank to the bottom. This behavior can be ascribed to typical buoyancy-driven convection due to temperature difference, and the upper part of the module melted in a wide-open shape as it proceeded in the order of (1)-(2)-(3), shown in the schematic diagram.

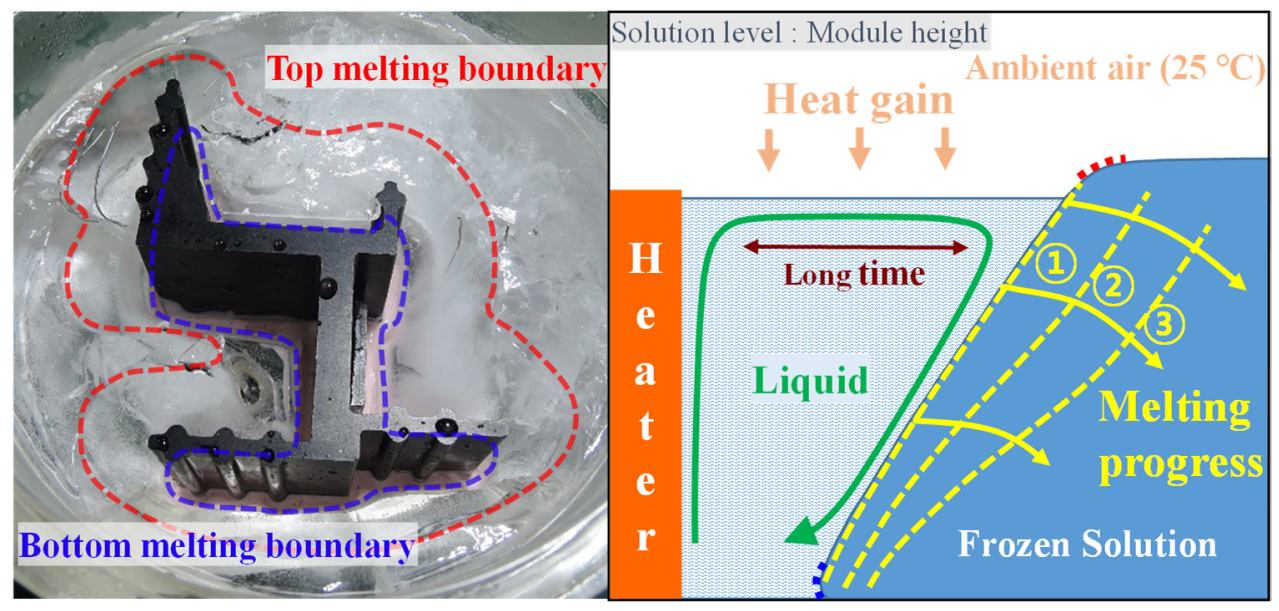

Figure 7. Top view of frozen solution, and schematic of phenomenon with time (Module_1); condition: Case_1 (level: Module height)/420 s.

Figure 8 shows an image of the result obtained in Case_2 and a schematic diagram explaining the melting process. According to the test result, in Case_2, unlike Case_1, the upper part of the module was closed in the form of a dome, and the contents under the dome were not exposed to external air; consequently, the lower part melted at a faster rate. In addition, a gas layer formed between the module and the solid solution owing to the volume difference induced by the phase change of the frozen solution and the gas generated when the solution included some evaporation gas on the surface of the module during the melting process. The occurrence of this phenomenon can be ascribed to the level of the freezing solution being higher than that of the heating module. Accordingly, the shape shown in Figure 8 can be attributed to the fact that the gas generated during the melting process was trapped in the frozen space, and it constrained the buoyancy-driven flow of the fluid. At the start of the melting process, the melted solution rose to the top along the heating module, but because the upper part of the module was surrounded by the frozen solution, in Case_2, considerable heat loss occurred within a significantly shorter time than in Case_1. For this reason, the solution in the melted state, which had lost acceleration due to buoyancy, could not form a large flow around the heating module. As melting progressed, a greater volume of gas was generated in the upper part of the module, and the liquid solution, which is relatively more effective for heat transfer, formed a comparatively large flow at the bottom of the module. Melting proceeded in the order of (1)-(2)-(3) from the bottom of the module, as indicated in the schematic diagram.

Figure 9 shows a schematic diagram explaining the shape of melting and the melting process when the ambient temperature is low $\left(-20{ }^{\circ} \mathrm{C}\right.$ or lower). This figure presents the results of the melting test conducted inside the freezer to maintain a low ambient temperature, and the test condition corresponds to Case_1. The initial appearance of melting at an extremely low ambient temperature was similar to that at room temperature, 
but the shape of melting was different. Under low ambient temperature, unlike under room temperature, the solution did not melt with a wide-open shape at the top, and the characteristics of melting were similar to those observed under Case_2. At the start of melting, the melted solution along the module rose to the top due to buoyancy, but heat loss occurred quickly due to the low ambient temperature at the top. For this reason, the solution that had lost acceleration due to buoyancy could not form a large flow around the upper part of the heating module. Subsequently, the melted solution at the bottom of the module formed a large flow, and this characteristic was consistent with Case_2 in many parts. We confirmed that the heat loss at the top of the heating module had a sizeable effect on the shape of melting, which clearly indicates that a flow did not develop at the top because of the heat loss.

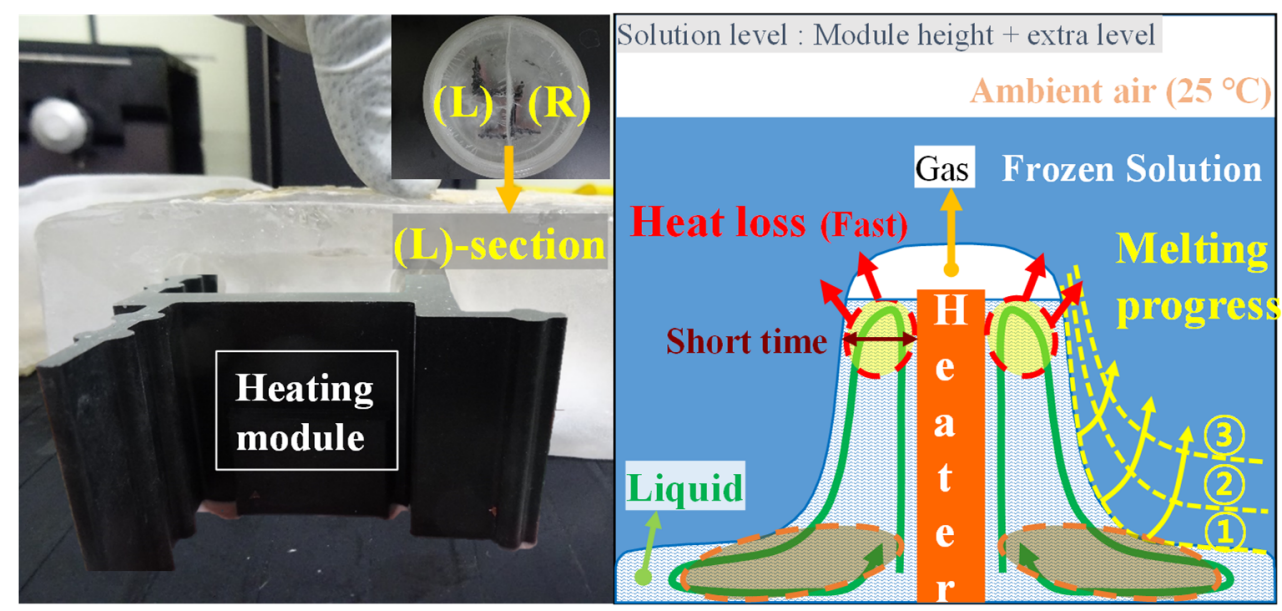

Figure 8. Section view of frozen solution and schematic of phenomenon according to time (Module_1); condition: Case_2 (level: Module height + extra level)/420 s.

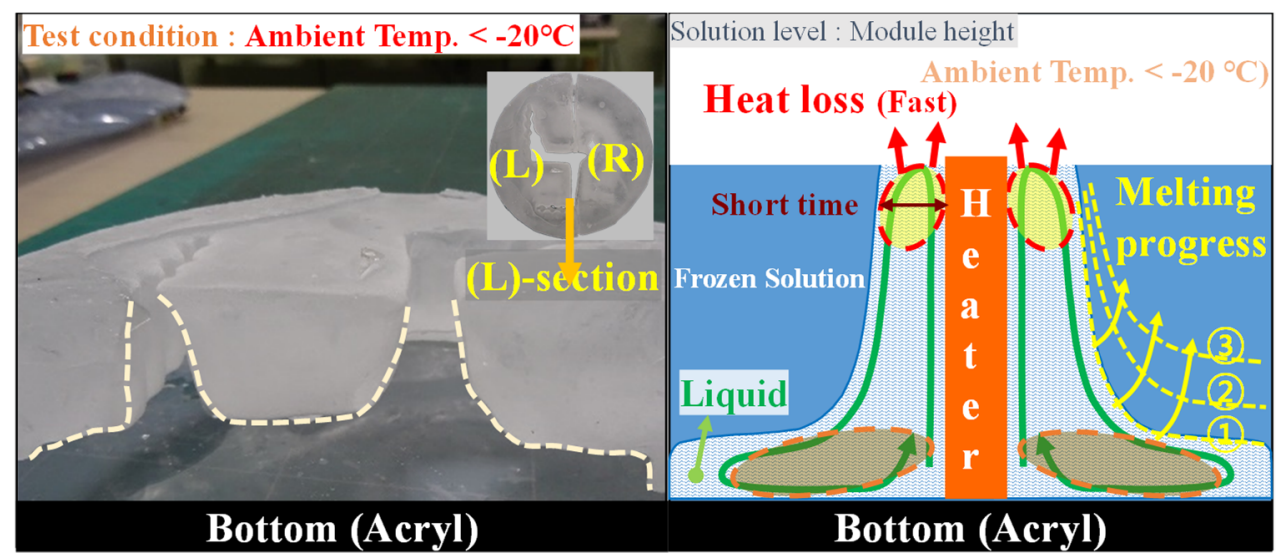

Figure 9. Section view of frozen solution, and schematic of phenomenon with time (Module_1); condition: Case_1 (level: Module height)/ambient temp. $<-20{ }^{\circ} \mathrm{C} / 600 \mathrm{~s}$.

Figure 10 shows the test result obtained under Case_2 and the shape of the frozen solution that changed with the passage of melting time. The figure confirms that the change in the top thickness of the frozen solution covering the upper part of the heating module was not large. This indicates that the melting did not proceed smoothly in the part where the gas layer existed on the upper part of the module. Moreover, the melting process in this area was slow because the gas layer was not as effective at heat transfer as the melted liquid solution. Unlike the upper part, a large flow developed in the lower part of the module for the same reason as described in Figures 8 and 9, and the melting process proceeded smoothly. As a result, we confirmed that the thickness of the entire 
frozen solution decreased as the melting height increased, even though the top thickness did not change significantly with time. When Module_1 and Module_2 were tested under the same conditions, the melting shapes exhibited the same tendency. In addition, although there was a slight difference in the rate of temperature rise depending on the module, the shape of melting did not change significantly with the passage of time.

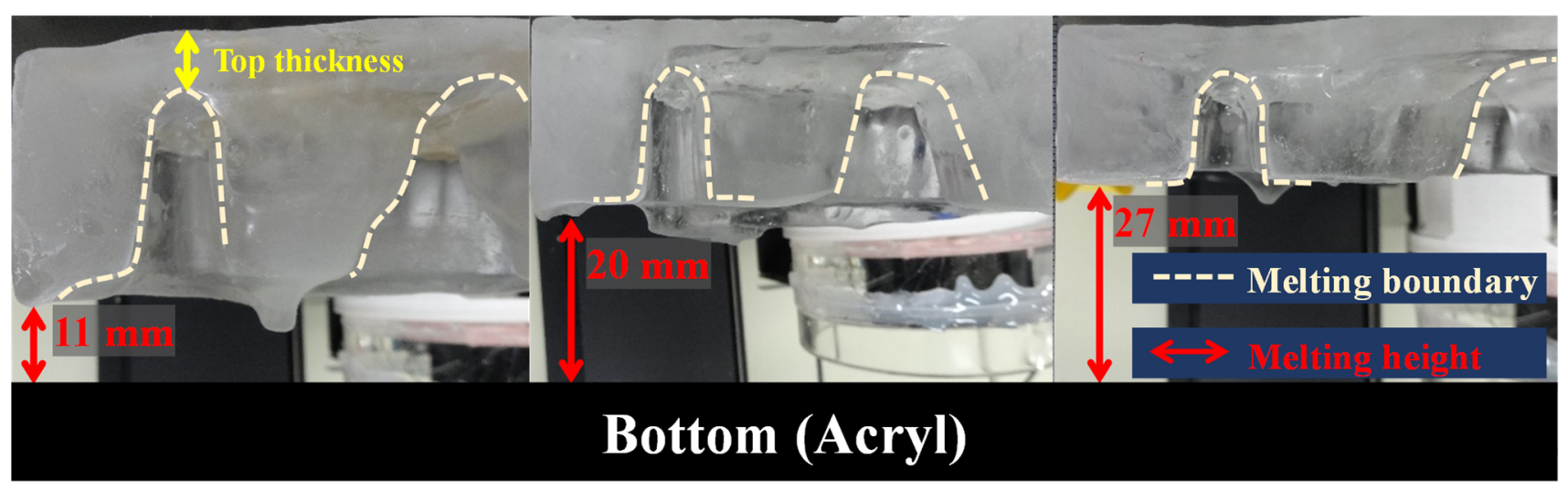

$420 \mathrm{~s}$

$600 \mathrm{~s}$

$720 \mathrm{~s}$

Figure 10. Section view of frozen solution according to heating time (Module_1) (Case_2) (420,600, 720 s).

\subsection{Temperature Distribution Characteristics}

Figure 11 shows a two-dimensional representation of the temperature change and distribution characteristics around the heating module with the passage of time after the application of power. A total of nine sensors positioned at regular intervals around the module, as shown in Figure 6, were used to check the temperature characteristics. The right side of Figure 6 shows a two-dimensional representation of the positions of the installed sensors when the module is viewed from the bottom. Ignoring the $\mathrm{z}$ distance of each sensor, the positions are expressed by projecting them on the $x-y$ plane. In this case, because points 5 and 8 are expressed as the same point, we used these two points as the average of the two measured values. In order to confirm the relationship between the melting shape and temperature, the test was conducted using only Module_2, the element temperature of which was limited to $160{ }^{\circ} \mathrm{C}$, and the level conditions were those corresponding to Case_1 and Case_2. In addition, data were acquired at 60, 240, 420,600, and 720 s after the start of melting to determine the temperature distribution at each time. As the melting proceeded after power was supplied, it was confirmed that the temperature around the module (the part close to the module) increased relative to that in the part far from the module. Overall, we confirmed that the temperature increased rapidly when the phase change was completed, especially after the rate of temperature increase due to phase change decreased to near $0{ }^{\circ} \mathrm{C}$. This trend can be ascribed to the anomalous behavior of water, which was the solution used herein, near $0^{\circ} \mathrm{C}$. Although UWS mostly consists of water, its freezing and melting point is $-11.7^{\circ} \mathrm{C}$, meaning that one can expect to observe the above-described anomalous behavior at a temperature close to $-11.7^{\circ} \mathrm{C}$.

According to the results of the two cases shown in Figure 12, the initial melting proceeded similarly, but the same temperature boundary in the $\mathrm{x}$ direction was narrower in Case_2 than it was in Case_1. This is because the heat loss in the upper part of the module was large, and for this reason, the melted solution on the upper part did not spread wide and descended faster toward the bottom. Although there was heat loss in Case_1, we confirmed that the temperature spread over a wide shape because the ambient temperature was room temperature. In Case_1, the temperature boundary was not clearly distinguishable from $600 \mathrm{~s}$ onward, which seems to indicate that the temperature difference between the melted upper solution and the unmelted solution was not large due to heat inflow from the outside and relatively low heat loss. By contrast, in Case_2, the upper- 
temperature boundary was clearly maintained even at $600 \mathrm{~s}$ and $720 \mathrm{~s}$, meaning that the temperature difference was maintained owing to rapid heat loss.
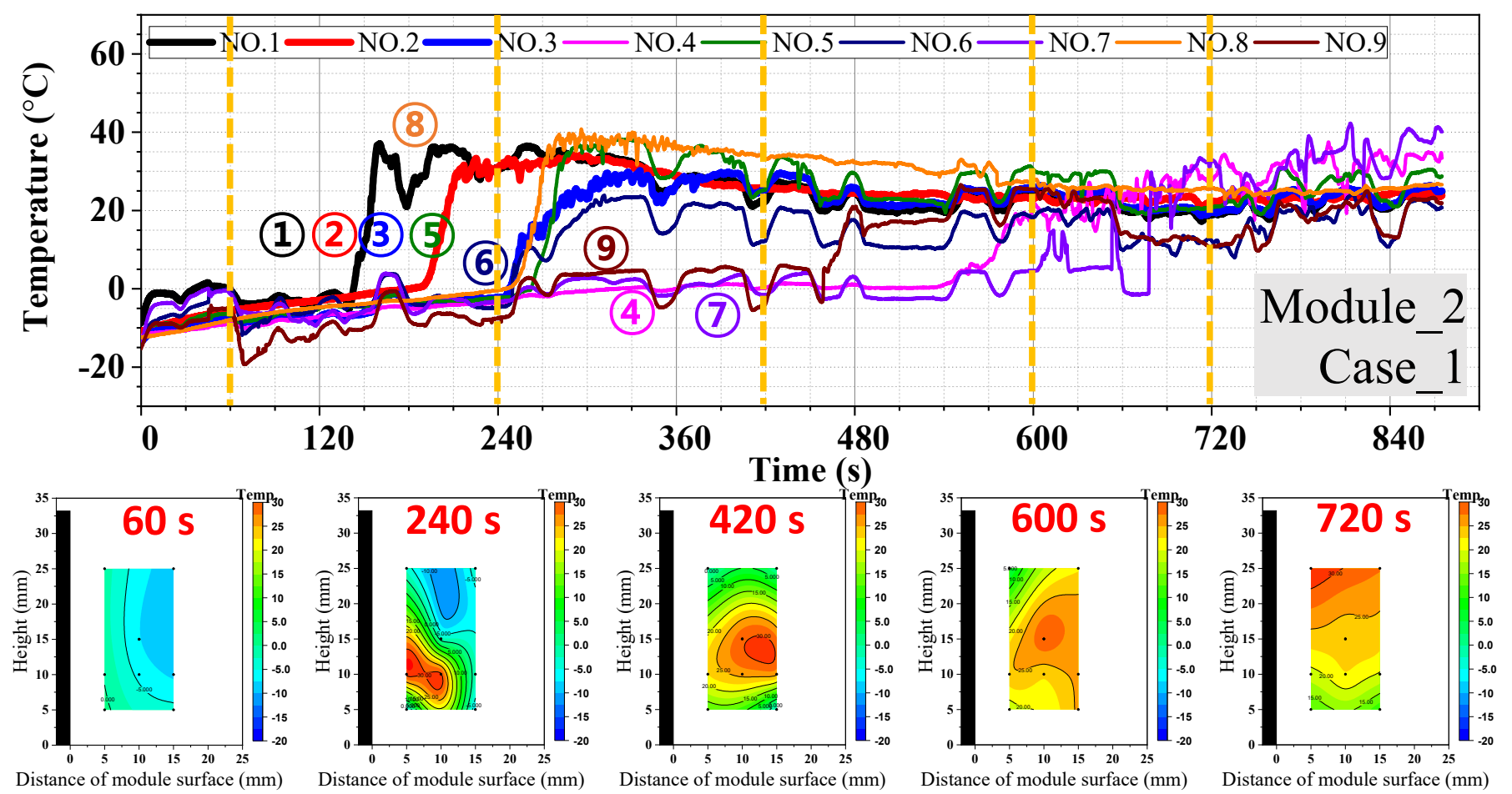

Figure 11. Temperature distribution around the heating module (Module_2) (Case_1).
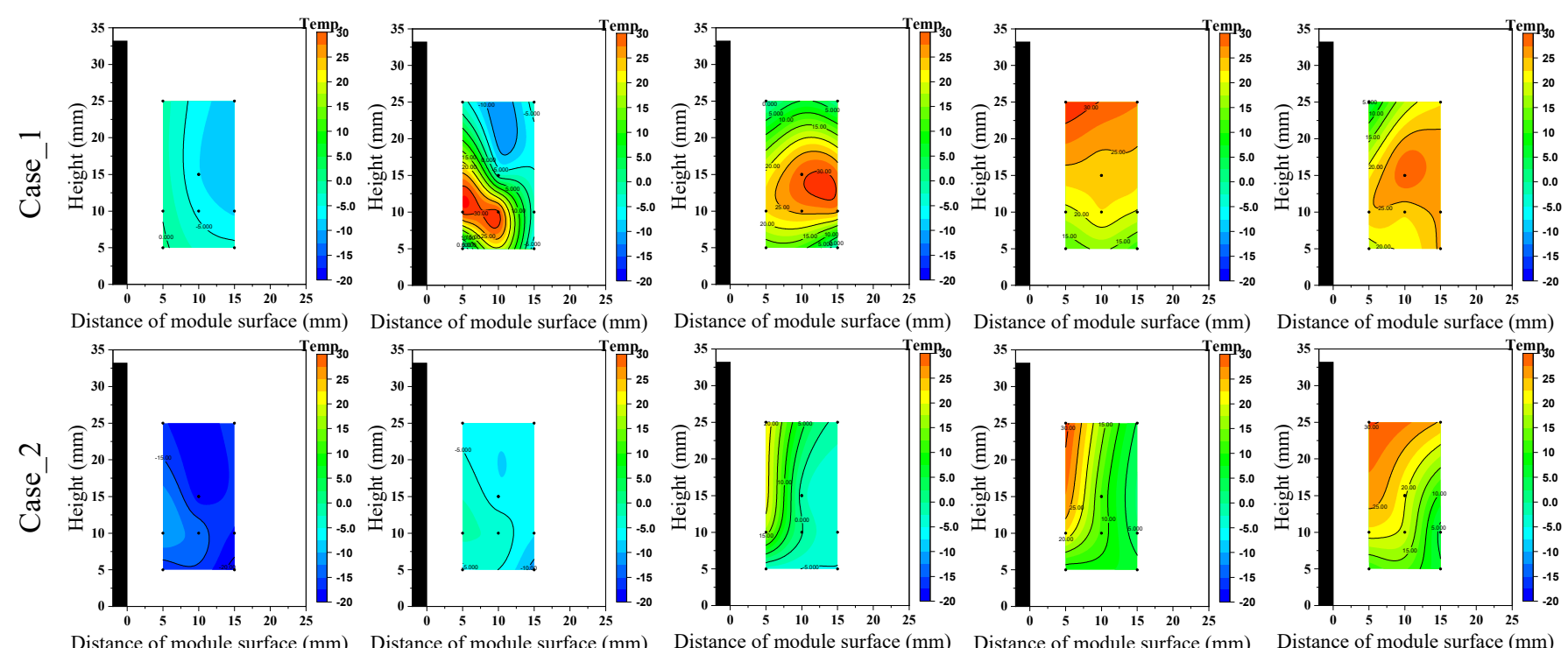

$60 \mathrm{~s}$

$240 \mathrm{~s}$

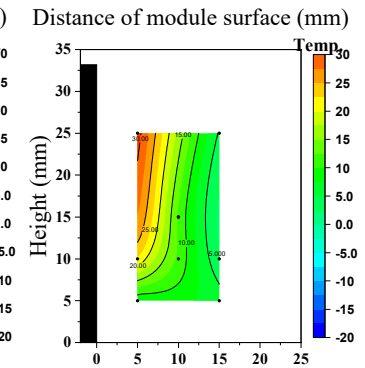

$\mathbf{6 0 0} \mathrm{s}$

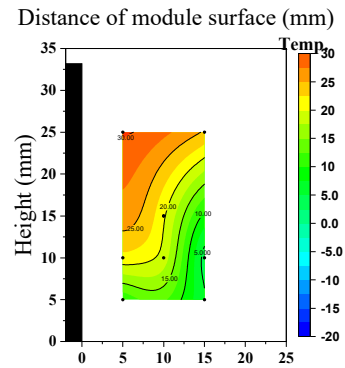

$720 \mathrm{~s}$

Figure 12. Temperature distribution around heating module (Module_2): Case_1 vs. Case_2.

This is because, in Case_1, heat from the outside affected the temperature in the relevant area, but in Case_2, only the heating module and the solution in the frozen state affected the temperature.

The test was conducted both at room temperature and under the internal conditions of the refrigerator, where the ambient temperature was lower than $-20^{\circ} \mathrm{C}$. Although the overall temperature was lower than that recorded in the experiment conducted at room temperature, the two sets of results exhibited a similar trend. Lee et al. reported that the temperature at the top of the heater was higher owing to the effect of convection and 
density change due to the temperature difference, and their results exhibited a trend similar to the flow results recorded near the heating module in this study [23].

\subsection{Mass of Melt with the Passage of Time}

The graph in Figure 13 shows the power consumed over time since the start of the power supply to each heating module. The power consumed by Module_1 at the start of heating increased rapidly as soon as power was switched on, and then, it decreased gradually. On the contrary, Module_2 did not consume much power initially compared with Module_1, and the power consumption increased gradually over time. This phenomenon can be ascribed to the fact that the current changes with temperature owing to the resistance characteristics of the heating element (PTC), as described in Figure 4. Therefore, the maximum temperature of Module_1 was lower than that of Module_2. However, Module_1 consumed a considerable amount of power in the initial heating period, whereas the power consumption of Module_2 increased gradually with the passage of heating time. This finding confirmed that the power consumption of Module_1 was higher than that of Module_2 after approximately 180 s since the start of the power supply; thereafter, the power consumption of Module_2 was higher.

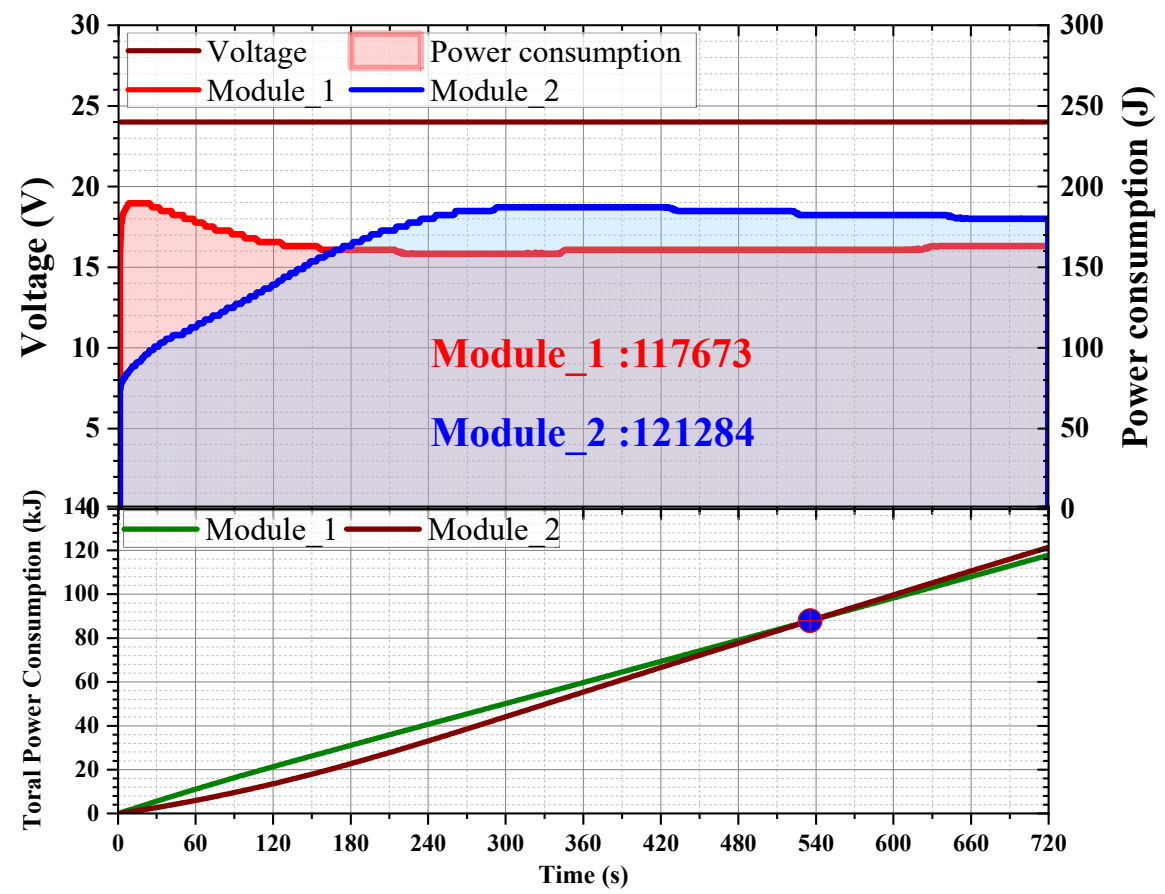

Figure 13. Power consumption with the passage of heating time.

High power consumption indicated that a large amount of energy was used for melting, and power consumption and amount of melted solution exhibited similar trends. In addition, the total power consumption of Module_1 and Module_2 was the same over approximately $540 \mathrm{~s}$, and the masses of melt were similar at $600 \mathrm{~s}$. Table 3 lists the power consumption and the masses of melt with the passage of heating time.

Figure 14 shows a graph of the mass of melt and power consumption over time summarized in Table 3. As described above, in the case of Module_1, the power consumed in the initial stage of heating was greater than that in the case of Module_2. At this time, the mass of melt exhibited a similar trend as that of power consumption. Thereafter, with the passage of heating time, the mass of melted solution due to heating by Module_2 exceeded that of the melted solution due to heating by Module_1. 
Table 3. Melting amount and energy consumption.

\begin{tabular}{|c|c|c|c|c|c|c|}
\hline \multirow{2}{*}{$\begin{array}{c}\text { Time } \\
\mathrm{s}\end{array}$} & \multicolumn{2}{|c|}{ Melting Amount } & \multicolumn{4}{|c|}{ Energy } \\
\hline & \multicolumn{2}{|c|}{$\mathrm{g}$} & \multicolumn{2}{|c|}{ kJ } & \multicolumn{2}{|c|}{$\mathrm{mg} / \mathrm{kJ}$} \\
\hline \multicolumn{7}{|c|}{ Solution: Distilled Water } \\
\hline 300 & 87.0 & 74.0 & 57.946 & 47.540 & 1.4997 & 1.5566 \\
\hline 420 & 151.8 & 118.0 & 81.972 & 70.620 & 1.8519 & 1.6709 \\
\hline 600 & 188.4 & 184.4 & 95.880 & 101.083 & 1.9650 & 1.8242 \\
\hline 720 & 225.1 & 229.9 & 117.673 & 121.284 & 1.9129 & 1.8956 \\
\hline \multicolumn{7}{|c|}{ Solution: Urea Water Solution } \\
\hline 600 & $\begin{array}{c}207.7 \\
\text { Module_1 }\end{array}$ & $\begin{array}{c}181.1 \\
\text { Module_2 }\end{array}$ & $\begin{array}{c}100.970 \\
\text { Module_1 }\end{array}$ & $\begin{array}{c}88.860 \\
\text { Module_2 }\end{array}$ & $\begin{array}{c}2.0570 \\
\text { Module_1 }\end{array}$ & $\begin{array}{c}2.0380 \\
\text { Module_2 }\end{array}$ \\
\hline
\end{tabular}

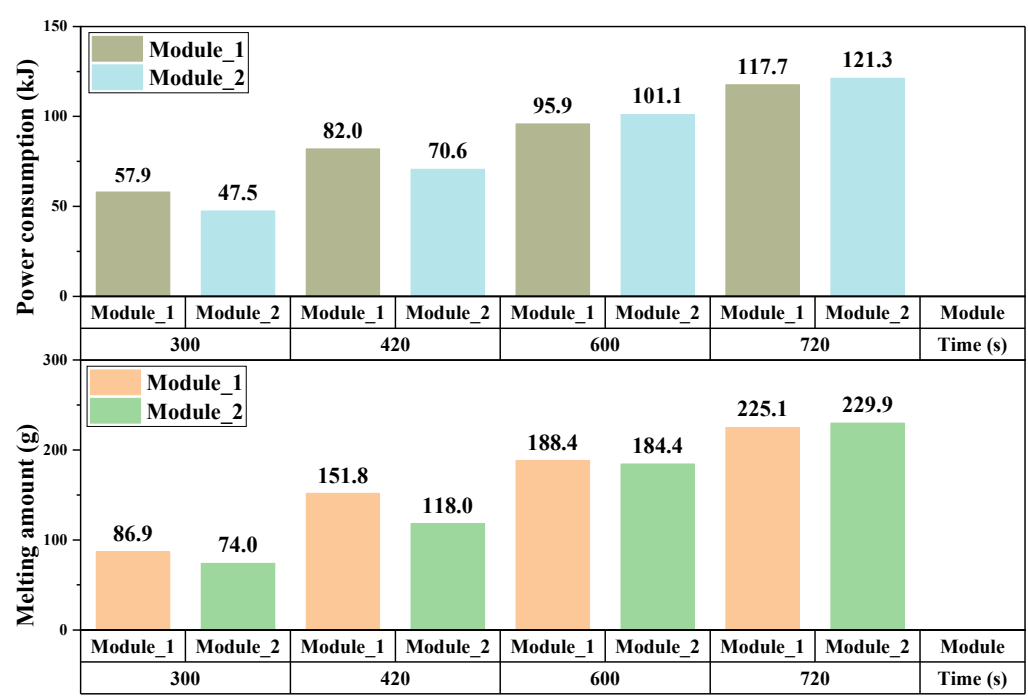

Figure 14. Mass of melt and power consumption with the passage of heating time.

\section{Conclusions}

We arrived at the following conclusions by conducting a test using distilled water, the main component of UWS, as a solution for convenience to understand the melting characteristics over time:

(1) When the initial freezing conditions of the heating module corresponded to Case_1 and Case_2, different flow characteristics were observed around the module during melting;

(2) In Case_1, convection by buoyancy occurred because of heating, and the rate of heat loss was relatively slow. As a result, the melted solution flowed over a wide shape, and the cross section of the solution melted into a sectoral shape with an open top;

(3) In Case_2, a gas layer formed between the module and the unmelted solid solution owing to the volume difference between the gas generated during melting and the phase change. In addition, the solid solution blocked contact between the melted solution and external ambient air;

(4) In Case_2, the heated liquid solution was buoyant and rose to the top, but the frozen solution covering the upper part of the module caused rapid heat loss. Consequently, a wide flow did not form in the upper part, but it formed in the lower part, and the melting process was concentrated in the lower part;

(5) Compared with the results of previous studies, in the case of numerical analysis, the general convection phenomenon was the same, and the mass of melt was confirmed to be predictable to some extent through numerical analysis;

(6) However, most of the previous studies did not consider the gas and volumetric volume generated during melting, and it was confirmed that the shape of melting 
was different from that obtained in the experiment. Therefore, in the future, studies should consider the shape of melting for the buoyancy effect.

Author Contributions: B.G.J. and K.C.O. Conceptualized the idea and method. S.U.J. provided module heating software. B.G.J. organized and analyzed the entire process of the experiment. He also wrote the paper, while K.C.O. supervised throughout the process. All authors have read and agreed to the published version of the manuscript.

Funding: This study was supported under the "Development and Demonstration of Simultaneous $\mathrm{PM}$ and $\mathrm{NO}_{\mathrm{x}}$ Reduction system of Military Vehicles (2020003060002)" project of the Ministry of Environment's Fine Dust Blind Spot Reduction Project.

Conflicts of Interest: The authors declare no conflict of interest.

\section{References}

1. Heywood, J.B. Internal Combustion Engine Fundamentals; McGraw-Hill Book Company: New York, NY, USA, 2005 ; pp. 586-642.

2. Shim, E.J.; Park, H.W.; Bae, C.S. Effects of Hot and Cooled EGR for HC Reduction in a Dual-Fuel Premixed Charge Compression Ignition Engine; SAE Technical Paper: Warrendale, PA, USA, 2018. [CrossRef]

3. Marasri, S.; Ewphun, P.P.; Srichai, P.; Charoenphonphanich, C.; Karin, P.; Tongrooon, M.; Kosaka, H. Combustion characteristics of hydrotreated vegetable oil-diesel blends under EGR and low temperature combustion conditions. Int. J. Automot. Technol. 2019, 20, 569-578. [CrossRef]

4. Mohamad, A.C.M.A.; Ali, K.; Himmet, Ö.; Keskin, Z. Properties of ethyl alcohol-water mixtures as a reductant in a SCR system at low exhaust gas temperatures. Energy Sources Part A Recovery Util. Environ. Effects 2020, 1-12. [CrossRef]

5. Da, S.; Li, B.; Liu, Z. Large eddy simulation of transient turbulent flow and mixing process in an SCR denitration system. Chem. Eng. Res. Des. 2019, 141, 279-289.

6. Yuan, M.; Su, Y.; Deng, W.; Zhou, H. Porous clay heterostructures (PCHs) modified with copper ferrite spinel as catalyst for SCR of $\mathrm{NO}$ with $\mathrm{C}_{3} \mathrm{H}_{6}$. Chem. Eng. J. 2019, 375, 122091. [CrossRef]

7. Andreata, M.; Millo, F.; Mallamo, F.; Mercuri, D.; Pozzi, C. Experimental Investigation on Three Different Ceramic Substrate Materials for a Diesel Particulate Filter; SAE Technical Paper: Warrendale, PA, USA, 2013. [CrossRef]

8. Yamaguchi, S.; Fujii, S.; Kai, R.; Miyazaki, M.; Miyairi, Y.; Miwa, S.; Busch, P. Design Optimization of Wall Flow Type Catalyzed Cordierite Particulate Filter for Heavy Duty Diesel; SAE Technical Paper: Warrendale, PA, USA, 2005. [CrossRef]

9. Yang, H. LNT NO $\mathrm{N}_{x}$ Storage Modeling and Estimation via NARX; SAE Paper: Warrendale, PA, USA, 2010. [CrossRef]

10. Lundström, A.; Andersson, B.; Olsson, L. Urea thermolysis studied under flow reactor conditions using DSC and FT-IR. Chem. Eng. J. 2009, 150, 544-550. [CrossRef]

11. Ko, S.C.; Oh, K.C.; Seo, C.K.; Lee, C.B. Characteristics on $\mathrm{NO}_{\mathrm{x}}$ adsorption and intermediates of LNT catalyst. Int. J. Automot. Technol. 2014, 15, 347-352. [CrossRef]

12. Guan, B.; Zhan, R.; Lin, H.; Huang, Z. Review of state of the art technologies of selective catalytic reduction of $\mathrm{NO}_{\mathrm{x}}$ from diesel engine exhaust. Appl. Therm. Eng. 2014, 66, 395-414. [CrossRef]

13. Jun, W.; Yipan, H.; Yixi, C.; Chuang, Z.; Lei, Z.; Chen, Z.; Hang, F. Influence of urea-SCR system parameters on NOx conversion rate and liquid film. Energy Sources Part A Recovery Util. Environ. Effects 2019, 43, 2027-2040. [CrossRef]

14. Han, J.; Kim, E.; Lee, T.; Kim, J.; Ahn, N.; Han, H.; Heesung, C. Urea-SCR Catalysts with Improved Low Temperature Activity; SAE Technical Paper: Warrendale, PA, USA, 2011. [CrossRef]

15. Blakeman, P.; Arnby, K.; Marsh, P.; Newman, C.; Smedler, G. Vanadia-Based SCR Systems to Achieve EUIV HDD Legislation; SAE Technical Paper: Warrendale, PA, USA, 2009. [CrossRef]

16. Koebel, M.; Elsener, M.; Kleemann, M. Urea-SCR: A promising technique to reduce $\mathrm{NO}_{\mathrm{x}}$ emissions from automotive diesel engines. Catal. Today 2000, 59, 335-345. [CrossRef]

17. Enderle, C.; Vent, G.; Paule, M. BLUETEC Diesel Technology_Clean, Efficient and Powerful; SAE Technical Paper: Warrendale, PA, USA, 2008. [CrossRef]

18. Stefan, W. Numerical heat transfer and thermal engineering of AdBlue(SCR) tanks for combustion engine emission reduction. Appl. Therm. Eng. 2007, 27, 1790-1798.

19. El-Sharkawy, A.; Kalantzis, P.D.; Syed, M.A.; Snyder, D.J. Thermal Analysis of Urea Tank Solution Warm Up for Selective Catalytic Reduction (SCR); SAE Paper: Warrendale, PA, USA, 2009. [CrossRef]

20. Choi, B.C.; Kim, Y.K.; Jhung, W.N.; Lee, C.H.; Hwang, C.Y. Experimental investigation on melting characteristics of frozen urea-water-solutions for a diesel SCR de-NO ${ }_{x}$-system. Appl. Therm. Eng. 2013, 50, 1235-1245. [CrossRef]

21. Choi, B.C.; Woo, S.M. Numerical analysis of the optimum heating pipe to melt frozen urea-water-solution of a diesel urea-SCR system. Appl. Therm. Eng. 2015, 89, 860-870. [CrossRef]

22. Lee, S.Y.; Kim, M.Y. Numerical investigation on the urea melting characteristics with coolant and electric heaters. Trans. Korean Soc. Mech. Eng. 2016, 40, 1-7. (In Korean) [CrossRef]

23. Lee, D.K.; Kim, M.Y.; Oh, K.C. A numerical study on the melting and heat transfer characteristics of the urea-water solution with electric heating module. In Proceedings of the 16th International Heat Transfer Conference, Beijing, China, 10-15 August 2018. 